\title{
Mammogram: Association of Music with Anxiety among Malaysian Woman - A Systematic Review
}

\author{
Nur Fatin Ruslizam, Nur Nadiah Fatihah Ab Malek, Norhayati Mohd Zain, \\ Nur Anis Izzati Che Mut, Norhashimah Mohd Norsuddin, Siti Aishah Abdullah Suhaimi, \\ Munirah Ahmad Dahari, and Nur Amalina Hasan
}

\begin{abstract}
Mammography is one of the screening tool that using $x$-ray dose to detect breast cancer at early stage for women older than 40 years old. By performing mammography screening annually, it can decrease mortality from breast cancer. Pain and anxiety often a hindrance to the rate of intake of mammography screening among the women. A systematic review was conducted to know the association of music with anxiety and pain on patients during mammography screening. Review identification was performed through a database search on MEDLINE and CINAHL, and 2 qualified studies were selected. The keyword used is "music therapy", "anxiety", "pain", and "mammography". A total of 2 articles showed the use of music among women who undergoing mammography screening. The previous studies showed that the use of music can decrease level of pain and anxiety among women during mammography screening. Thus, applying music during the screening should be implemented to encourage women for annual mammography screening.
\end{abstract}

Index Terms - music therapy; mammography; anxiety; pain.

\section{INTRODUCTION}

Breast cancer is the most common cancer and it occur to all age groups in women. The rates of breast cancer are higher especially in developed countries [1]. Besides that, based on another study, the yearly accident rate of breast cancer rise in Asia and African compared to North America and Europe [2]. This can be seen in Malaysia where according to National Cancer Registry Report 2007-2011, the incidence rate of breast cancer rises from 3,579 in year 2007 to 3,766 in 2011 [3]. Furthermore, according to Rahmah et al. [1] the percentages of patients delayed diagnosis of breast cancer is higher in Malaysia, where $72.6 \%$ for three months and $45.5 \%$ for six months.

An early detection in order to improve breast cancer outcome and survival remains the cornerstone of breast cancer control [4]. Mammogram screening designed as a program to allow early detection for breast cancer and reduce mortality, and can be it can applied to the population at acceptable costs for society [5]. This screening recommended for women who age above 40 years old. According to Clinical

Published on April 18, 2020.

N.F. Ruslizam, Medical Imaging Department, KPJ Healthcare University College, Malaysia. (e-mail: nurfatin 27@yahoo.com)

N.N.F. Ab Malek, Medical Imaging Department, KPJ Healthcare University College, Malaysia. (e-mail: nadiahmalek97@gmail.com)

*N. M. Zain (Corresponding author), Medical Imaging Department \& Research Management Centre, KPJ Healthcare University College, Malaysia. (e-mail: norhayati@kpjuc.edu.my)

N.A.I. Che Mut, Research Management Centre KPJ Healthcare University College, Malaysia. (e-mail: nur.anis@kpjuc.edu.my)
Practice Guidelines [6] for the women age 40-49 years who at low and intermediate risk, they should not be offered routinely and women age 50-74 years must done biennially.

Although this screening have capability to improve women's health and reduce breast cancer problem, many women are not willing to undergo mammogram because of pain and anxiety which related to breast compression technique, previous mammography experiences, and lack of knowledge on how mammogram screening done [7][8]. As a result, they will stop from attending their upcoming mammography appointments [9]. To overcome this barrier, music is use as intervention to reduce pain and anxiety level among women who undergoing mammogram screening. Besides that, it been proof that music easy to apply, inexpensive and improve patient satisfaction [10]. Thus, we conducted the systematic review to review the pattern of the association of music with pain and anxiety among women undergoing mammogram screening.

\section{MATERIALS AND METHOD}

This systematic review was conducted according to 2009 PRISMA guidelines.

\section{A. Search Strategy}

The search strategy used for this systematic review was conducted to know the association of music with anxiety and pain on patients during mammography screening. A literature search was performed via MEDLINE and CINAHL databases by using "music therapy", "anxiety", 'pain", and "mammography" keywords. A flow diagram of the literature search strategy is shown in Figure 1.

Diverse methodological features were used to assess the quality of reviewed study which defined the sample population, the objectives and the outcomes of the study. The data was extracted using the PICOS technique as in Table 1. The data extractions contain the name of the author, year of publication, objectives, study design, population, statistical analysis used, and outcomes. Differences in interpretations were determined via discussions, and thereafter an agreement

N. M. Norsuddin, Diagnostic Imaging \& Radiotherapy Program, Universiti Kebangsaan Malaysia, Selangor, Malaysia. (e-mail: norhashimahnorsuddin@ukm.edu.my)

S.A. Abdullah Suhaimi, Medical Imaging Department, KPJ Healthcare University College, Malaysia. (e-mail: ucn.aishah@kpjuc.edu.my)

M. A, Dahari, Psychology Department, KPJ Healthcare University College, Malaysia. (e-mail: ucn.munirah@kpjuc.edu.my)

N.A. Hasan, Psychology Department, KPJ Healthcare University College, Malaysia. (e-mail: ucn.amalina@kpjuc.edu.my) 
was reached.

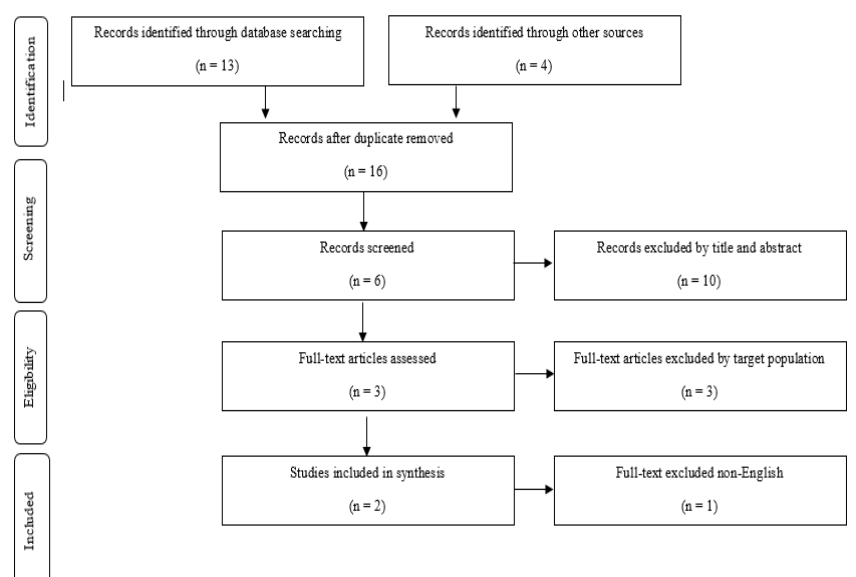

Fig 1: Diagram of the Literature search strategy

TABLE I: DATA OF EXTRACTION

\begin{tabular}{|c|c|}
\hline Author & Results \\
\hline Domar et al. (2005) [16] & $\begin{array}{l}\text { Subjects who listened to a relaxation } \\
\text { audiotape before and during their } \\
\text { screening mammography did not report } \\
\text { any benefits from the intervention } \\
\text { when compared with subjects who } \\
\text { listened to music or a control group. }\end{array}$ \\
\hline
\end{tabular}

Zavotsky et al. (2014) [15] The result showed that music can decrease anxiety and pain level among women who undergoing mammogram screening.

\section{DISCUSSION}

Breast cancer is the most commonly diagnosed cancer among women globally. Early detection can be done to reduce the mortality rate among women such as mammograms [11]. Mammograms can be performed for women aged 40 years and above. A mammogram is a type of screening that involved compression to the breast to detect masses or lump. Even though the sensitivity and specificity of a mammogram is higher than clinical breast examination, the prevalence of mammogram screening in Malaysia was lower with $7.6 \%$ in 2006 compared to the United Kingdom, France and, Sweden which was between 80\%-95\% [1].

Pain and anxiety are the most common factors among women when undergoing mammography screening. Several studies have shown that meditation, aromatherapy, and music therapy have therapeutic effects and reduce a patient's anxiety during medical procedures. Aromatherapy is derived from the word aroma which means fragrance and therapy which means treatment. This therapy uses essential oils extracted from plants and fruits to provide natural healing of a person's mind and body [12]. Many plant oil are commonly utilised as anxiolytics, such as lavender, rose, bergamot and, sandalwood [13]. As stated by Wotman et al. [14], lavender and unscented aromatherapy can decrease a patient's anxiety before breast surgery.

Many studies have shown that music therapy is an effective tool that can reduce pain and anxiety in medical procedures. Zavotsky et al. [15] studied the effect of music on pain and anxiety among women undergo mammography screening. A quasi-experimental prospective study was collected from
2011 to 2012 and included 100 participants, whereby 50 participants listen to music and another 50 did not listen to the music. This study revealed that there is no significant difference in anxiety score between intervention and control group. Although it is not significant, there is a difference adjusted mean score which the mean score for the anxiety in the intervention group which was lower than control group.

Meanwhile, Domar et al. [16] performed a relaxation technique to reduce pain and anxiety during mammography screening. The subjects were divided into relaxation, music and control groups. The result showed that the mean score of both groups for STAI and Likert scores were low. Besides that, it showed that white women had higher anxiety scores after mammography screening compared to other races, and anxiety scores for older women was lower than younger women. Other than that, subjects who listened to audiotapes before and during mammography screening did not exhibit benefits compared to the music and control group. This demonstrates that the use of music can influence the level of pain and anxiety during the mammogram.

\section{CONCLUSION}

In conclusion, based on previous studies on the use of music during mammography screening, the results seem to suggest that the use of music can reduce pain and anxiety among women during mammography screening. Music can provide distraction to patient, and offers calm during the screening. Thus, applying music during the screening should be implemented to encourage women for annual mammography screening.

\section{ACKNOWLEDGEMENT}

This research work is financially supported by the KPJ Healthcare University College Research Grant (KPJUC/RMC/SOHS/EC/2019/225). The authors would like to express their sincere gratitude to all who have contributed to this study formally and informally. The authors declare no conflict of interest.

\section{REFERENCES}

[1] M. A. Rahmah, I. Aniza, and C. E. M. Che Engku Nor Bahiyah, "Do ealderly women in Malaysia go for mammogram screening?," Malaysian Journal of Public health Medicine, vol. 13, no. 2, pp. 20-26, 2013.

[2] R. A. Al-Naggar, Y. V. Bobryshev, "Practice and barriers of mammography among Malaysian women in the general population," Asian Pacific Journal of Cancer Prevention, vol. 13, no. 8, pp. 35953600, 2013

[3] A. M. Azizah, I. T. Nor Saleha, A. Noor Hashimah, Z. A. Asmah, and W. Mastulu, Malaysian National Cancer Registry Report 2007-2011: Malaysia Cancer Statistics, Data and Figure, Putrajaya: National Cancer Institute, 2015, pp. 33.

[4] B. O. Anderson, C.H. Yip, R. A. Smith, R. Shyyan, S. F. Sener, A. Enju, et al., "Guideline implementation for breast healthcare in lowincome and middle-income countries: overview of the Breast Health Global Initiative Global Summit 2007," Cancer, vol. 113, no. 8, pp. 2221-2243, 2008.

[5] S. H. Heywang-Kobrunner, A. Hacker, S. Sedlacek, "Advantages and disadvantages of mammography screening," Breast Care, vol. 6, no. 3, pp. 199-207, 2011.

[6] Clinical Practice Guidelines, Management of Breast Cancer, $2^{\text {nd }}$ Edition, Putrjaya: Ministry of Health Malaysia, 2010, pp. 7. 
[7] M. Yilmaz, and O. Kiymaz, "Anxiety and pain associated with process mammography: Influence of process information before," The Journal of Breast Health, vol.6, no. 2, pp. 62-68, 2010.

[8] S. B. Abdel-Aziz, T. T. Amin, M. B. Al-Gadeeb, A. I. Alhassar, A. AlRahman, M. Al-Helal, et al., "Perceived barriers to breast cancer screening among Saudi women at primary care setting," Asian Pacific Journal of Cancer Prevention, vol. 18, no. 9, pp. 2409-2417, 2017.

[9] P. Whelehan, A. Evans, M. Wells, and S. MacGillivray, "The effect of mammography pain on repeat participation in breast cancer screening: A systematic review," The Breast, vol. 22, pp. 389-394, 2013.

[10] J. Demarco, J. 1. Alexander, G. Nehrenz, and L. Gallagher, "The benefit of music for the reduction of stress and anxiety in patients undergoing elective cosmetic surgery," Music \& Medicine, vol. 4, no. 1, pp. 44-48, 2012.

[11] N. M. Zain, V. P. Seriramulu, and K. K. Chelliah, "Bone Minera Density and breast cancer risk factors among premenopausal and postmenopausal women-A systematic review," Asian Pacific Journal of Cancer Prevention, vol 17, no. 7, pp. 3229-3234, 2016.

[12] B. Ali, N. A. Al-wabel, S. Shams, A. Ahamad, S. A. Khan, and F. Anwar, "Asian Pacific Journal of Tropical Biomedicine," Asian Pacific Journal of Tropical Biomedicine, vol. 5, no. 8, pp. 601-611, 2015.

[13] C. Ni, W. Hou, C. Kao, M. Chang, L. Yu, C. Wu, and C. Chen, "The anxiolytic effect of aromatherapy on patients awaiting ambulatory surgery: A randomized controlled trial," Evidence-Based Complementary and Alternative Medicine, pp. 1-5, 2013.

[14] M. Wotman, J. Levinger, L. Leung, A. Kallush, E. Mauer, and A. Kacker, "The efficacy of lavender aromatherapy in reducing preoperative anxiety in ambulatory surgery patients undergoing procedures in general otolaryngology," Laryngoscope Investigative Otolaryngology, vol. 2, no. 6, pp. 437-441, 2017.

[15] K. E. Zavotsky, A. Banavage, P. James, K. Easter, V. Pontieri-Lewis, and L. Lutwin, "The effects of music on pain and anxiety during screening mammography," Clinical Journal of Oncology Nursing, vol 18, no. 3, pp. E45-E49, 2014.

[16] A. D. Domar, A. Eyvazzade, S. Allen, K. Roman, R. Wolf, J. Orav, and J. Baum, "Relaxation techniques for reducing pain and anxiety during screening," American Journal of Roentgenology, vol. 184, no.2, pp. $445-447,2005$.

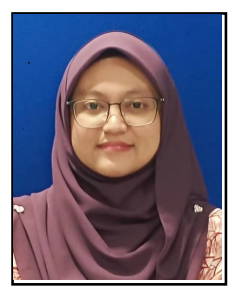

N. M. Zain is the Associate Professor and Senior Lecturer in Medical Imaging Department, School of Health Sciences, KPJ Healthcare University College. She is also the Director of Research Management Centre. She graduated in Doctor of Philosophy (Diagnostic Imaging) in 2019 from National University of Malaysia and Master in Health Sciences (Diagnostic Imaging) in 2014 from National University of Malaysia. She also had her Bachelor of Diagnostic Imaging \& Radiotherapy in 2007 from National University of Malaysia. She is experienced in breast imaging and breast cancer related research activities and has been awarded with numbers of internal university research grants. She has also published number of original and review articles related to breast imaging and breast cancer related research. 